\title{
JUVENILE POLYP FROM SYMPTOM TO DIAGNOSIS AND THE ROLE OF ULTRASONOGRAPHY: A CASE REPORT
}

\author{
Berkin Ersoy ${ }^{1}$ Özdal Ersoy², Haluk Akman ${ }^{3}$, Füsun Baba ${ }^{4}$ \\ ${ }^{1}$ University of Hamburg School of Medicine, Hamburg, GERMANY \\ ${ }^{2}$ Department of Gastroenterology, Acıbadem Mehmet Ali Aydınlar University School of Medicine, Istanbul, \\ TURKEY \\ ${ }^{3}$ Department of Radiology, Acıbadem International Hospital, Istanbul, TURKEY \\ ${ }^{4}$ Department of Pathology, Acıbadem International Hospital, Istanbul, TURKEY
}

\begin{abstract}
Aims: Juvenile polyps are the most common intestinal polyps in children, but they are also found relatively frequently in adults. Although colonoscopy and pathologic examinations are essential for the final diagnosis of juvenile polyps, our aim is to show that ultrasound imaging can also reveal the juvenile polyps. Case Report: In a 21-year-old female patient with painless rectal bleeding and abdominal pain, blood tests showed no signs of anemia or infection, but the fecal occult blood test was found to be positive. Ultrasound imaging prior to colonoscopy revealed the juvenile polyp. The polyp was resected during colonoscopy via hot snare polypectomy and then it was pathologically diagnosed as a juvenile polyp. Conclusion: Ultrasonography is not a very common diagnostic tool for colonic polyps, but it may have the potential of revealing a colonic polyp such as a juvenile polyp. This can ease the process of diagnosis. Keywords: Juvenile polyp, ultrasonography, colonoscopy
\end{abstract}

\section{INTRODUCTION}

Juvenile polyps (JPs) are the most prevalent intestinal polyps in children and they are most frequently diagnosed in the first 10 years of life, but they also account for approximately $1 \%$ of all colonic polyps found in adults. JPs are more commonly seen in males and they are also more common on the left side of the colon (1).

The term "juvenile" refers to the histological characteristics of the polyp and not the age of onset (1). Regardless of age, the most common symptoms for JPs are blood in stool and abdominal pain. The gold standard of the confirmation of the diagnosis is a pathological examination of the polyp resected during colonoscopy, but ultrasonography may also help to reveal juvenile polyps (2). This case report underlines the effectiveness of ultrasound imaging during the diagnostic work-up of JPs since ultrasound is not a very common diagnostic tool for colonic polyps (3).

\section{CASE REPORT}

A 21-year-old female patient was admitted to the gastroenterology department of Acıbadem International Hospital due to blood in stool and abdominal pain. She had no fever, no loss of appetite, or weight loss and she was not taking any medications or herbs. Abdominal examination including digital rectal examination showed no pathological findings. Initially requested blood tests revealed no signs of anemia or infection (Table 1) but the fecal occult blood test was found to be positive and total abdominal ultrasonography pointed a hypoechoic nodule-like intraluminal polypoid lesion in sigmoid colon with $17 \times 21 \mathrm{~mm}$ dimension with arterial blood flow on Doppler investigation (Figure 1). The colonoscopy that was performed afterwards showed a big polyp with a long stalk in the sigmoid colon which was resected via hot snare polypectomy (Figure 2). No other polyps were seen in the whole colon during the colonoscopy. Finally, pathological examination of the polyp was compatible with a JP with an edematous lamina propria with inflammatory cells and cystically dilated glands filled with mucus (Figure 3). 
Table 1: Laboratory evaluation.

\begin{tabular}{lcc}
\hline & Results with units & Reference values with units \\
Leukocytes & $10.30 \times 10^{\wedge} 3 / \mathrm{uL}$ & $4.50-11.00 \times 10^{\wedge} 3 / \mathrm{uL}$ \\
Hemoglobin & $14.0 \mathrm{~g} / \mathrm{dL}$ & $12.5-16 \mathrm{~g} / \mathrm{dL}$ \\
Platelets & $347 \times 10^{\wedge} 3 / \mathrm{uL}$ & $150-400 \times 10^{\wedge} 3 / \mathrm{uL}$ \\
Glucose (pre-prandial) & $94 \mathrm{mg} / \mathrm{dL}$ & $70-100 \mathrm{mg} / \mathrm{dL}$ \\
Alanine Aminotransferase $(\boldsymbol{A L T})$ & $28 \mathrm{IU} / \mathrm{L}$ & $12-59 \mathrm{IU} / \mathrm{L}$ \\
Aspartate Aminotransferase $(\boldsymbol{A S T})$ & $23 \mathrm{IU} / \mathrm{L}$ & $10-37 \mathrm{IU} / \mathrm{L}$ \\
C-reactive protein $(\boldsymbol{C R P})$ & $0.50 \mathrm{mg} / \mathrm{dL}$ & $<0.50 \mathrm{mg} / \mathrm{dL}$ \\
& & \\
\hline
\end{tabular}

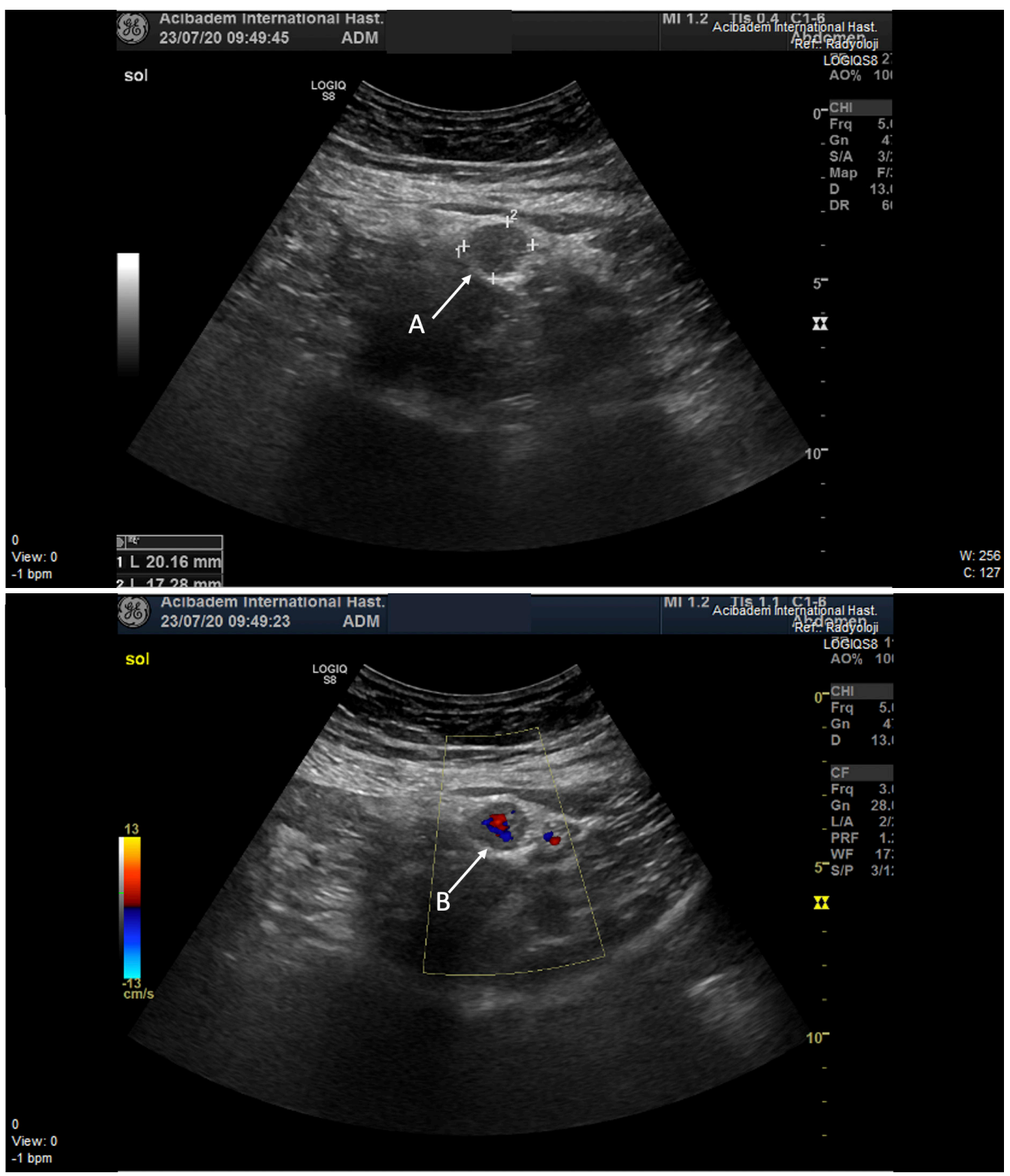

Figure 1: Ultrasound imaging. A: Abdominal ultrasound imaging indicating hypoechoic nodule. B: Vascularization of hypoechoic nodule on Doppler imaging. 


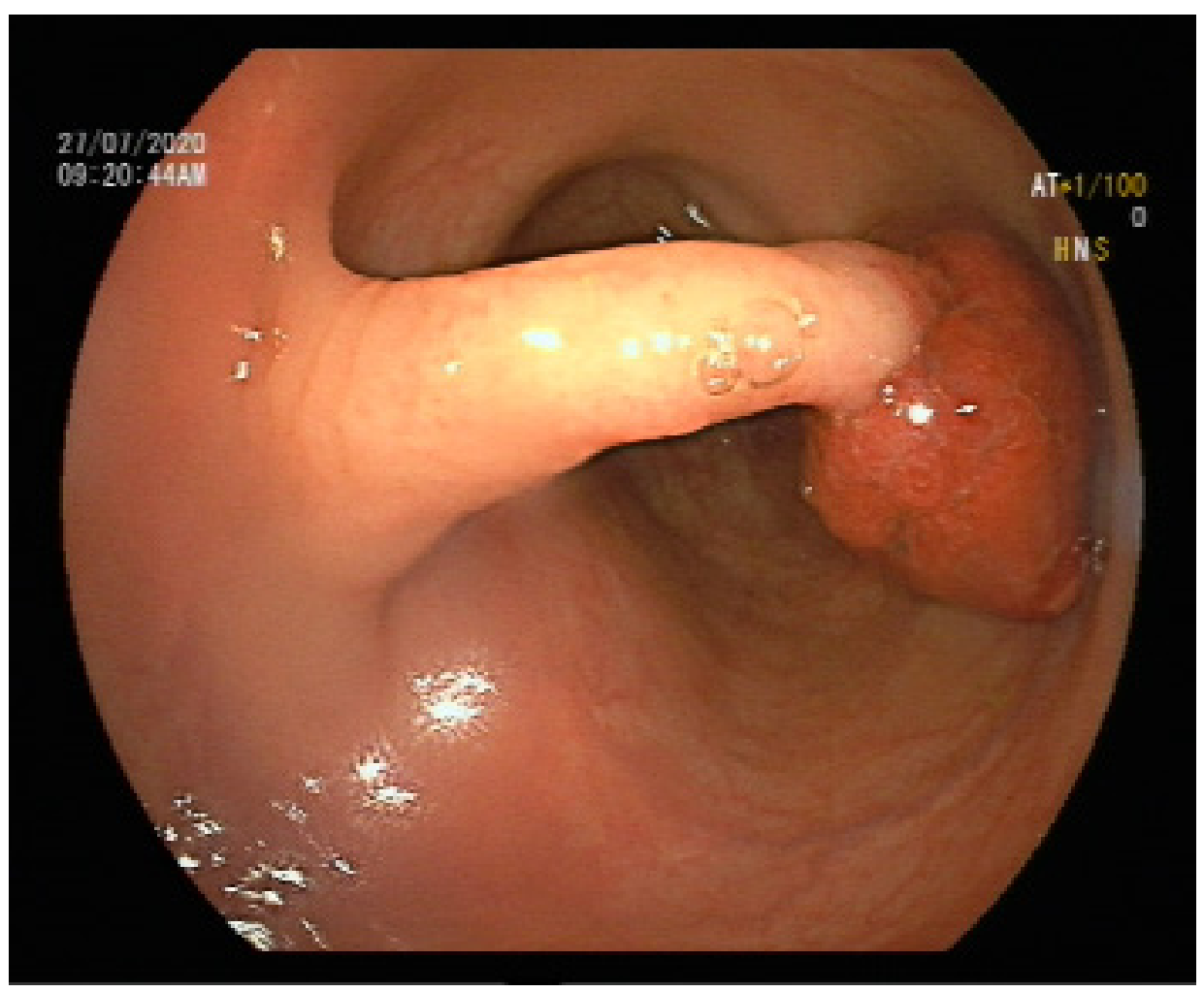

Figure 2: Endoscopic appearance of pedunculated polyp.

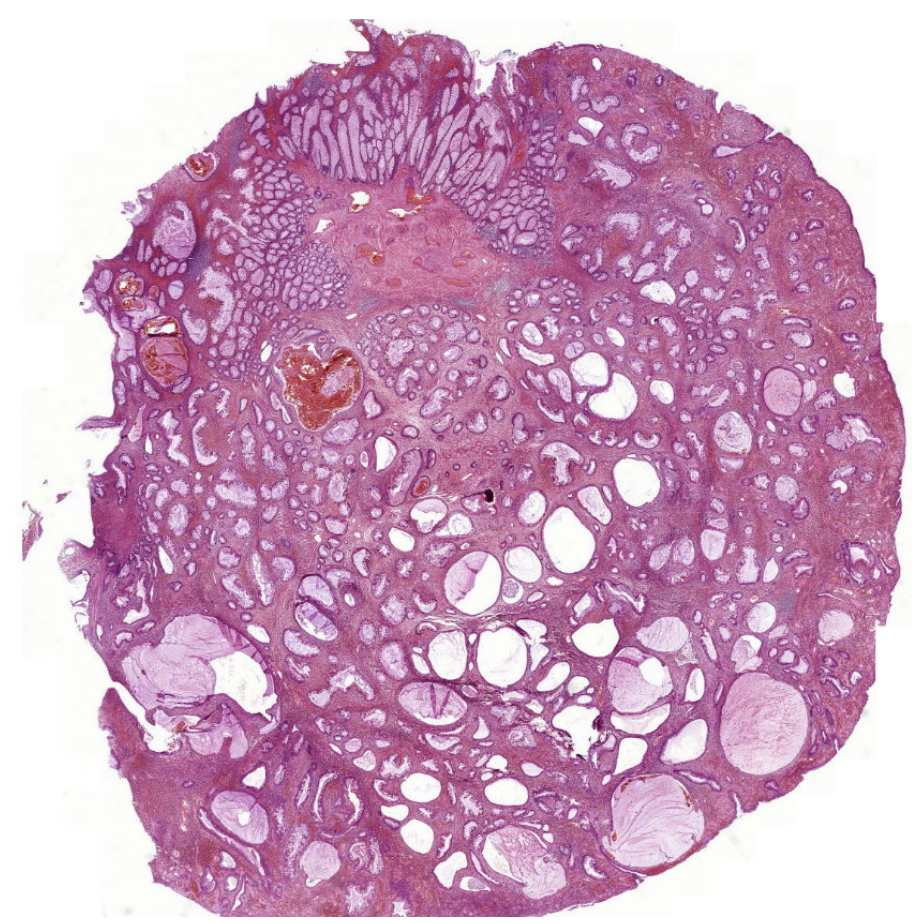

Figure 3: Pathological appearance of the polyp with cystically dilated glands with inflammation. 


\section{DISCUSSION}

Juvenile polyps account for approximately $80 \%$ of polyps in children, but are more likely to be found and diagnosed on adults since colonoscopy is a more common way of diagnosis in adult age $(1,4)$. JPs are usually listed under hamartomas, which is one of the two major categories for gastrointestinal polyps (5). Patients of all ages with JPs typically complain of bloody stools and abdominal pain (2). Differential diagnosis of these symptoms commonly includes inflammatory bowel diseases and acute gastroenteritis in young patients. Therefore, blood and stool examinations together with ultrasound imaging are initial diagnostic investigations. In these young patients, a colonoscopy is rarely performed except when it is truly necessary (6). Our patient's blood tests showed no specific pathology whereas the fecal occult blood test was positive and ultrasound imaging revealed the polypoid lesion in the colonic lumen and colonoscopy was performed afterwards. According to Vitale V et al. (7), ultrasound findings could be able to differentiate a colonic polypoid lesion from intraluminal feces or inflammatory pseudopolyps which also look like nodules.

In this young case, besides blood tests and abdominal ultrasound imaging, diagnostic evaluations also included colonoscopy due to positive fecal occult blood test. However, in young patients with abdominal pain but with no rectal bleeding or any alarming symptoms and signs for colonic malignancies (weight loss, loss of appetite, anemia); a colonoscopy is not urgently indicated or planned. For these situations, ultrasound imaging can point a polypoid lesion and guide the referral physician to perform the colonoscopy $(8,9)$.

Since only one polyp was found during the colonoscopy, the final diagnosis of our patient was a solitary JP. Solitary juvenile polyps have minimal malignant potential (10). On the other hand, juvenile polyposis syndrome increases the colorectal cancer risk (11). Juvenile polyposis syndrome diagnosis is made if any of the following criteria is present; 5 or more juvenile polyps in the colorectum or juvenile polyps throughout the gastrointestinal tract or any number of juvenile polyps and a positive family history of juvenile polyposis (12). Thus, it is important to distinguish solitary JP from juvenile polyposis syndrome by performing total colonoscopy rather than proctosigmoidoscopy. Our patient was informed about this very low malignancy potential of her polyp and she was also informed that polypectomy was the definitive treatment and no further routine follow-up was needed.
As a conclusion, ultrasonography is not a very common diagnostic tool for colonic polyps, but it may have the potential of revealing a colonic polyp such as a juvenile polyp. This can ease the process of diagnosis.

\section{Ethics Committee Approval: N/A}

Informed Consent: Verbal informed consent was obtained from the patient through a phone call.

Conflict of Interest: The authors declared no conflict of interest.

Author Contributions: Concept: BE Design:BE Supervision: OE Resources:OE, HA, FB Materials:BE, OE, HA, FB Data collection and/or processing: $\mathrm{BE}, \mathrm{OE}, \mathrm{HA}, \mathrm{FB}$ Analysis and/or Interpretation:BE Literature Search: BE Writing Manuscript:BE Critical Review:BE, OE.

Financial Disclosure: The authors declared that this study received no financial support.

Editor in chief's Note: One author of this article, Berkin Ersoy is a member of the editorial board of Turkish Medical Student Journal. However, he did not take place in any stage of the editorial decision of the manuscript. The editors who evaluated this manuscript are from other institutions.

\section{REFERENCES}

1. Jelsig AM, Ousager LB, Brusgaard K et al. Juvenile polyps in denmark from 1995 to 2014. Dis Colon Rectum 2016;59(8):751-7.

2. Chen W, Wang D, Jia L et al. Colorectal polyps in children: a retrospective study of clinical features and the value of ultrasonography in their diagnosis. J Pediatr Surg 2012;47(10):1853-8.

3. Parra DA, Navarro OM. Sonographic diagnosis of intestinal polyps in children. Pediatr Radiol 2008;38(6):680-4.

4. Lelli JL. Polypoid diseases of gastrointestinal tract. In: Jay LG, James AO, Arnold GC, editors. Pediatric Surgery. Philadelphia: Mosby; 2006.p.1414-26.

5. Malandra M, Kaur S, Chogle A. Utility of routine colonic biopsies in pediatric colonoscopic polypectomy for benign juvenile hamartomatous polyps. J Pediatr Gastroenterol Nutr 2017;64(4):555-8.

6. Thomson M, Tringali A, Dumonceau JM et al. Paediatric gastrointestinal endoscopy: European Society for paediatric gastroenterology hepatology and nutrition and European Society of gastrointestinal endoscopy guidelines. J Pediatr Gastroenterol Nutr 2017;64(1):133-53.

7. Vitale V, Di Serafino M, Mercogliano C et al. Giant colon polyp in a child with suspected inflammatory bowel disease: US findings. J Ultrasound 2014;19(1):53-5.

8. Wang $\mathrm{X}$, Jia $\mathrm{C}$, Yang $\mathrm{H}$ et al. Sonographic features of a juvenile polyp: a case report and literature review. Clin Imaging 2014;38(2):215-7.

9. Hosokawa T, Hosokawa M, Tanami Y et al. Diagnostic performance of ultrasound without any colon preparation for detecting colorectal polyps in pediatric patients. Pediatr Radiol 2019;49(10):1306-12.

10. Nugent KP, Talbot IC, Hodgson SV et al. Solitary juvenile polyps: not a marker for subsequent malignancy. Gastroenterology 1993;105(3):698-700.

11. Lin HC, Fiorino KN, Blick C et al. A rare presentation and diagnosis of juvenile polyposis syndrome and hereditary hemorrhagic telangiectasia overlap syndrome. Clin Imaging 2015;39(2):321-4. 12. Brosens LA, van Hattem A, Hylind LM et al. Risk of colorectal cancer in juvenile polyposis. Gut 2007;56(7):965-7. 